\title{
Post-graduate research in information and knowledge management in LIS schools in South Africa
}

\author{
Omwoyo Bosire Onyancha' \\ University of South Africa, Department of Information Science, Pretoria \\ onyanob@unisa.ac.za
}

\begin{abstract}
Received 10 March 2011
Accepted 12 July 2011

The purpose of this paper is to highlight salient patterns of post-graduate research in information and knowledge management (I\&KM) in LIS (Library and Information Science/Studies) schools in South Africa. The data was extracted from two SABINET (South African Bibliographic and Information Network)-hosted databases, namely the Current and Completed Research (C\&CR) and the Union Catalogue of Theses and Dissertations (UCTD). Data was analyzed in order to find out the coverage of I\&KM research in the databases; identify the topics of I\&KM research; to examine trends in I\&KM post-graduate research in South Africa; to determine the academic level at which I\&KM research is mostly conducted; to find out the qualifications under which I\&KM research is conducted; and to identify the study leaders (or supervisors) and institutions behind I\&KM research in South Africa. The study found that there is an increased interest in I\&KM by post-graduate students in South Africa; the main topics of research are related to Library and Information Science (LIS) and Business Science; the majority of the study leaders belong to the discipline of LIS; and that the most productive institutions are universities and more particularly, the universities that not only lead in the national research output but also those which have LIS departments. Recommendations for further research are also offered.
\end{abstract}

Keywords: Informetrics, South Africa, Post-graduate students, LIS education and training, knowledge management, information management

\section{Information and knowledge management education in LIS schools in South Africa: a brief overview}

It is generally acknowledged that knowledge management is a relatively new concept, having been introduced in the mid 1990s (Jacobs 2004; Ondari-Okemwa \& Minishi-Majanja 2007) although its practice is much older. Its introduction in LIS (Library and Information Science/Studies) schools as a subject of study or a course is therefore recent but phenomenal in its acceptance and growth. Citing Grossman, Ondari-Okemwa and Minishi-Majanja (2007: I39) observe that "over the past decade, knowledge management has emerged as an academic discipline with more and more universities and colleges offering specialized courses and programmes in the subject".

In South Africa, Ondari-Okemwa and Minishi-Majanja (2007: 145) indicate that LIS scholars in the country began developing interest in KM around 1996 "when two of the L/IS departments introduced aspects of KM in their curricular". The authors, in their study of knowledge management education in the departments of library/information science in South Africa, established that six LIS departments/schools in South Africa now offer subjects or courses in knowledge management at both undergraduate and post-graduate levels while one of the departments offers aspects of KM within its modules. The six LIS departments/schools that offer KM courses, according to Ondari-Okemwa and Minishi-Majanja's study, are located at the University of Cape Town (UCT), University of Johannesburg (UJ), University of KwaZulu-Natal (UKZN), University of Pretoria (UP), University of South Africa (UNISA), and the University of Zululand (UNIZUL). However, we have noted that there are some universities (e.g. University of Western Cape) that offer KM modules but were not included in the aforementioned study. One other department which offers KM courses but was not included in the aforementioned list is located at Stellenbosch University (SU). It is worth noting however that there is confusion about the number of LIS departments existing in South Africa as some departments/schools are said to have completely deviated from offering traditional LIS qualifications while others are on the verge of being closed down due to the transformations going on in higher education in South Africa (see Ondari-Okemwa and Minishi-Majanja 2007; Ocholla and Bothma 2007; Raju 2004; Raju 2005).

Furthermore, the emergence of KM as an academic discipline or subject has partly altered LIS education and training as well as research in South Africa. For instance, two departments/schools that formerly offered LIS education and training (ie the University of Johannesburg - formerly known as the Rand Afrikaans University - and the University of Stellenbosch) have since broken away from the LIS paradigm to offer qualifications in only information and knowledge management, thereby abandoning librarianship completely (Ocholla and Bothma, 2007). Although the department at the University of Stellenbosch maintains the name Information Science on its website, the Uniform Resource Locator (URL)

I. Omwoyo Bosire Onyancha $(\mathrm{PhD})$ is an associate professor in the Department of Information Science, University of South Africa, Pretoria. 
and the content of the department's website show that the Department's emphasis has changed and is focused on knowledge dynamics and decision-making as its name extension indicates. An excerpt from the welcome message on the Department's website states the following:

Our academic focus is Informatics within the broad context of the knowledge economy and society. The most important areas in which we specialise are Business and Governmental Information Systems, Knowledge Management and Decision-making (University of Stellenbosch, Centre for Knowledge Dynamics and Decision Making 2009).

Further information on the website reveals that the Department's focus is on informatics and that it offers three programmes "one in the Faculty of Economic Science and two in the Faculty of Social Sciences. All in all we have a presence in 5 faculties" (University of Stellenbosch, Centre for Knowledge Dynamics and Decision Making 2009). In its curriculum as described on its website, the Department offers the following courses

a.At the Bachelor's level (Information Systems Management; Socio-informatics; and Decision-making and Values);

b.Post-graduate studies (Honours, Masters research and Doctoral research degrees)

The department also offers short-learning courses and consultancy in the following specific subjects

a.Decision making in complex and hazy contexts

b.Information systems analysis

c.Knowledge base audit for organisations

d.Knowledge systems management in organisations

e.Organisational sense making

f.Scenario building

g.The knowledge economy and African development

h.Web design for knowledge based organisational systems

On its part, the Department of information and Knowledge Management at the University of Johannesburg strives to provide students with a "practical introduction to information and knowledge management" with specialisation in such areas as records and information management, knowledge management, business intelligence and competitive intelligence (University of Johannesburg, Department of Information and Knowledge Management, 2010). The Department offers the following qualifications at post-graduate level:

a.BA Honours in Information Management

b.BCom Honours in Information Management

c.MPhil in Information Management

d.MCom in Business Management (with specialisation in Information and Knowledge Management)

e.PhD in Information Management

It was also observed that the Department at $\mathrm{UJ}$ offers two qualifications, namely a BA in Information Management and BCom in Information Management, at undergraduate level. It was noticed that the two programmes do not specifically mention 'knowledge management'. Neither do the post-graduate programmes. This can be attributed to the synonymous usage of "information management" and "knowledge management".

An examination of the websites of other LIS departments in South Africa yielded very little information on I\&KM offerings. Information available at the Department of Information Science at UP, for instance, indicates that I\&KM is offered as a module in second semester of the third year of study. There are no details about the content of what is taught in the module. Similarly, the Department of Information Science at UNISA offers I\&KM as a third year module. In terms of the titles or names given to I\&KM modules or subjects, Ondari-Okemwa and Minishi-Majanja (2007) found that at undergraduate level, KM courses offered by LIS departments in South Africa are known variously as Information and Knowledge Management, Knowledge Management, Information Resources Management, Economics of Information, Knowledge Dynamics, and information and Knowledge Management in Practice. At post-graduate level KM-specific modules are variously titled as Basic Information and Knowledge Management, Advanced Information and Knowledge Management, Knowledge Dynamics, Knowledge Management, Economics of Information, Information Resources Management, Records Management, and Information and Knowledge Management. Apparently, the titles of the modules at undergraduate and post-graduate levels are not that different. 


\section{Information and knowledge management research}

Information and knowledge management research is taking centre stage in the field of Library and Information Science as well as other fields of study such as Computer Science and Business Administration (Jacobs 2004; Onyancha \& Ocholla 2009a). Gu (2004: 181) adds that, of recent,

scholars in many disciplines have shown an intense interest in the creation of knowledge and its value and power when it can be shared across the organization. Information and library science, information systems, computer science, engineering, communication, cognitive science, and organizational science have all laid claim to some aspect of KM.

As noted above, some schools or departments that were formally recognised as Library and Information Science/Studies (LIS) departments/schools have changed their names to departments/schools of Information and Knowledge Management. It is not surprising therefore that from the mid 1990s, there has been an intense interest in knowledge management from both the scholars and students of LIS. Previous studies such as those by Jacobs (2004), Gu (2004), and Onyancha and Ocholla (2006) have indicated that there has been a tremendous increase in the number of scholars interested in KM, particularly after the mid 1990s. For instance, in his study entitled 'global knowledge management research: a bibliometric analysis' Gu (2004: 174) observed that "during 1996 and 2002, the worldwide KM scholarly society expanded so rapidly and dramatically that the academic population increased by $2000 \%$ ". The author further noted that within the same period, there were as many as 2727 unique authors who had contributed a total of 1407 articles.

In a study of the growth and development of knowledge management research, Jacobs (2004: 21I) opines that the concept "knowledge management" has matured and can be investigated bibliometrically as the bibliometric perspective "provides an empirical structure that can be used to describe the emergence of and contributors to KM". Noting that KM took off around 1996, Jacobs (2004) observes that the popularity of KM increased rapidly from 1997 to 2000 . One other notable finding in Jacob's study was that eight of the top nine most productive countries were developed countries. South Africa took position nine and was the only African country that featured in the list of the top nine most productive countries.

In South Africa, Onyancha and Ocholla (2006) observed that information and knowledge management research was fast gaining popularity among LIS scholars. Using data extracted from the Current and Completed Research (C\&CR) and the Index to South African Periodicals (ISAP) databases, the authors observed that the number of documents (ie articles, theses and dissertations) covered in the two databases has continued to increase, a situation that persuaded the authors to conclude that the subject of information and knowledge management has become a 'hot topic' in South Africa. It should be noted, however, that Onyancha and Ocholla's (2006) study did not specifically focus on theses and dissertations (which are widely considered as a measurable indicator of post-graduate research) but included other types of research projects conducted in the subject field. At the time of conducting their study, Ondari-Okemwa and Minishi-Majanja (2007) identified only 22 research projects that were being conducted in KM in various LIS departments (ie UP, UNISA, UCT, U], UNIZUL, and UKZN). These findings led the authors to contend that the picture was an "indication of interest in the field".

So, why this study on an informetric analysis of the information and knowledge management research by postgraduate students? It should be noted from the onset that post-graduate research plays a very important role, both in terms of the knowledge generated and the development of the next generation of researchers. Byrnes (20I0), for instance, argues that postgraduate research and supervision constitutes a fundamental part of the university's 'core business' given that research is the lifeblood of a university and therefore post-graduate research and scholarship have a critical role to play in the larger research enterprise. Onyancha and Jacobs (2009: II8), too, observe that "writing a Masters or $\mathrm{PhD}$ thesis or dissertation and defending it out of an original research provides the author the official entrance into the scientific world of research and knowledge". Citing Lariviere, Zuccala and Archambault (2008), Onyancha and Jacobs (2009) opine further that a new scientist gains recognition from his/her mentors and peers and is confirmed as a member of a particular scientific field when he/she successfully completes his/her Masters and or PhD dissertation or thesis and disseminates the research findings by way of publishing in scholarly journals. From the aforementioned studies on $\mathrm{KM}$, we note that the emphasis of bibliometric/informetric studies that have been previously conducted to analyse KM research have focused on one type of indicator of research output, namely research articles as indexed in mainstream bibliographic and citation databases. The purpose of this study is therefore to examine information and knowledge management research using a different indicator of research output, namely the post-graduate dissertations and theses with a view to determine the trend, subject content, level, and the extent of as well as the persons behind information and knowledge management research in South African institutions of higher learning.

This study is driven by the following research questions:

SA JnI Libs \& Info Sci 20I I, 77(2) 
- What is the trend of research output in information and knowledge management by post-graduate students in South Africa?

- What subjects and topics are the most common in post-graduate research in information and knowledge management in South Africa?

- Which institutions are involved in the supervision of information and knowledge management research projects in South Africa?

- Who is driving information and knowledge management postgraduate supervision?

- At which level (i. e Masters and PhD) is information and knowledge management research mostly conducted?

\section{Methodology}

This study follows the approach adopted by Onyancha (2006). Using informetric methods and more particularly publications count and content analysis, the study examines information and knowledge management publications with a view to determine the patterns of post-graduate research in the broad sub-field or topic of information and knowledge management. Relevant data was extracted from SABINET's two databases that index research conducted by postgraduate students at institutions of higher learning in South Africa, namely the Current and Completed Research (C\&CR) and the Union Catalogue of Theses and Dissertations (UCTD). It was noted that different subject terms are used to index information and knowledge management publications, thereby dictating the usage of different search queries in the two databases. Whereas the subject phrase knowledge management was used by the UCTD database, the term information management was used to index information and knowledge management theses and dissertations in the C\&CR database. The two terms were therefore used to extract data from the two databases, respectively. Also used to search for publications in the C\&CR database was the subject phrase code 11112 which stands for information management and knowledge management.

Once the data was downloaded and saved in text format using Notepad, data was cleaned by removing duplicates and irrelevant data downloaded from the database in the process of data collection. Upon the removal of irrelevant data and duplicates, the final list of records, comprising II 2 entries in UCTD and 210 in C\&CR was then subjected to analysis in order to find out the most commonly researched topics, the most prolific institutions, trends in research in information and knowledge management, the language of publication, the participating study leaders, the most commonly used title words to describe information and knowledge management literature, and the level (ie a Masters or doctorate) at which information and knowledge management research is mostly conducted. Data was analysed using various analytical technologies such as UCINET for Windows version 6, Pajek, Bibexcel and TextStat. Whereas UCINET for Windows' analytical tools such as network analysis were used to reveal title word clusters/groups, Pajek was used to visualise the relationships between the most commonly used title words. Data was analysed using TextStat in order to obtain frequencies of word occurrence within the information and knowledge management titles. A network analysis using the Freeman-Granovetter grouping (ie f-groups) technique was conducted in order to identify the groups of terms with strong ties and which can be taken to constitute the most preferred topics of research in I\&KM in South Africa. A total of 142 title words which appeared in three or more records were obtained by subjecting the titles to analysis using TextStat software which generated frequencies of word occurrences in the titles. UCINET for Windows software's in-built network analysis capability was then applied to a matrix containing the 142 words to produce a Freeman-Granovetter Groups illustrated in Fig 2.

It is worth mentioning that the names of institutions, and more particularly the universities, changed following the merger of institutions of higher learning in South Africa in 2004. Any dissertation or thesis previously completed prior to 2004 was indexed under the original name of the institution which offered the qualification. This scenario called for the combination of the frequency counts of records that bore the original and current names by which the institution came to be known after the merger. For instance, the University of Johannesburg, which came into being in January 2005, was as a result of a merger between the Technikon Witwatersrand and Rand Afrikaans University. Any items found indexed under the two names as well as under the current name of the university were merged. The Rand Afrikaans University recorded a total of 13 theses and dissertations while the University of Johannesburg's total number of theses and dissertations was 23. The total number of records indexed under the name of the University of Johannesburg was therefore 36.

\subsection{Limitations of the study}

As the title suggests, the study was limited to Masters and Doctoral research projects as indexed and reflected in the UCTD and C\&CR databases. The C\&CR database indexes other research outputs collectively labelled "research projects" which are meant for non-degree purposes (eg research articles, reports, exchange visits, conferences, training, capacity building, book chapters, patents, working papers, tests, products, maps and lectures) (Onyancha \& Jacobs, 2009: 126). The data was extracted from the two databases between 17 and 19 February $201 \mathrm{I}$ and therefore reflects only 
those theses and dissertations that were captured by the date of data collection. The study was also limited to completed theses and dissertations, thereby excluding registered projects that had not yet been completed. Furthermore, the relatively small number of the completed theses and dissertations extracted for analysis does not necessarily reflect suitable benchmarking.

\section{Findings and discussion}

The results are presented and discussed under the following subheadings:

- Coverage of I\&KM post-graduate research in C\&CR and UCTD

- Research topics in I\&KM by post-graduate students

- Language of publication of I\&KM research

- Study leaders behind I\&KM research

- Level at which I\&KM research is conducted

4.1 Coverage of I\&KM post-graduate research in C\&CR and UCTD

The Penn diagram in Figure I shows the number of records extracted from the two databases. It reveals that there were a total of 210 records indexed in C\&CR while UCTD yielded a total of II 2 I\&KM research projects conducted by M\&D students in South Africa.

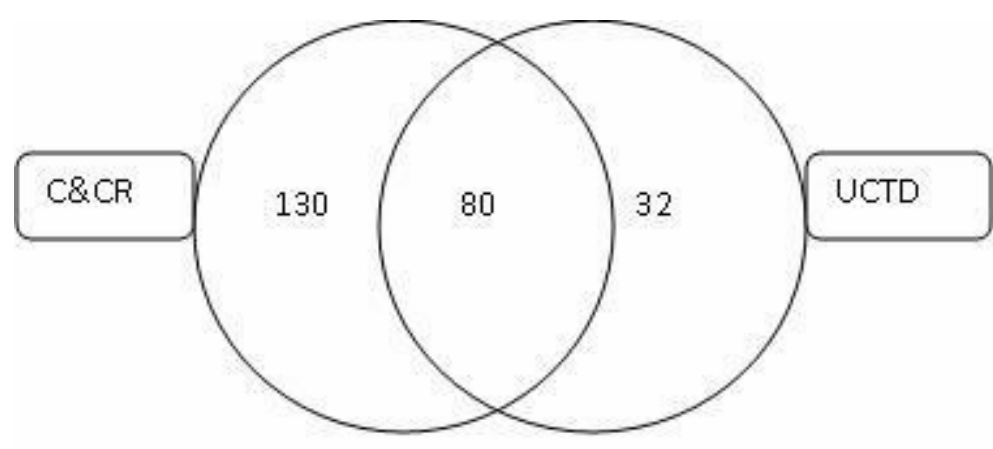

Figure 1 Penn diagram of the coverage of I\&KM research in C\&CR and UCTD

There were 130 and 32 records that were solely indexed in C\&CR and UCTD, respectively. The common records in the two databases numbered 80 , thereby producing a coverage overlap ratio ${ }^{2}$ of 0.33 and the strength of association (as explained by $\mathrm{Krsul}^{3}$ ) of 0.27 . Although these values indicate some kind of relationship between the two databases' coverage of I\&KM research, they nevertheless indicate that the contents of the databases are different as far as I\&KM research by post-graduate research in South Africa is concerned. Onyancha (2006), too, observed that the coverage overlap ratio in HIV/AIDS research between the UCTD and C\&CR was low and concluded that there were therefore differences as opposed to similarities in coverage of the contents of the two databases. It was also observed in the current study that C\&CR yielded more records than UCTD. It was not immediately clear why this is the case as the two databases are dedicated to indexing M\&D research, although the former also indexes non-qualification research projects.

4.2. Research topics in I\&KM by post-graduate students

An analysis of the subject headings reflect the areas or topics that are most preferred for research in a given subject field or discipline. The results may also be used not only to re-define the scope of a concept (see Onyancha \& Ocholla 2009a) but also to construct the concept's thesaurus entry by identifying the broader terms (BT), related terms (RT) and

2. . The coverage overlap is defined by Diodato (1994:52) as the number of items (e.g. journals) that are "indexed simultaneously by two indexing services" and can be expressed as

$$
\begin{aligned}
& \text { number of items in }(A \cap B) \\
& \text { number of items in }(A \cup B)
\end{aligned}
$$

whereby the figure thus generated is also known as the coverage overlap ratio.

3. ${ }^{3} S_{i j}=\frac{C_{i j}^{2}}{C_{i} C_{j}} O \leq S \leq 1$, where, $C_{i}$ is the number of records in which term $D_{i}$ appears; and $C_{j}$ is the number of records in which term $D_{j}$ appears (Krsul 2002; Coulter, Monarch \& Konda 1998; Onyancha \& Ocholla 2007). 
narrower terms (NT), as well as the alternative terms. The analysis of subject headings in the current study was meant to identify the concepts that can be used to describe the topics that are the most preferred by post-graduate students in I\&KM research in South Africa.

With the exception of the broad subject heading 'Information Science", Table I reveals that the most common research topics as reflected in C\&CR are Information Management which yielded a total of 210 records, accounting for $100 \%$ of the total number of records extracted from C\&CR. In the third position in the C\&CR category is Business Administration/Business Leadership ( 18 or $8.6 \%$ ), Business Management (6 or $2.9 \%$ ) and Library Science (5 or $2.4 \%$ ). The rest of the 25 subject headings that were used to index and therefore index I\&KM research in C\&CR yielded less than 3 records each. In the UCTD database, a total of 220 subject headings were used to describe I\&KM. Leading the pack was Knowledge Management which posted a total of 95 (84.8\%) while Organisational Learning were ranked second and third with $2 \mathrm{I}(\mathrm{I} 8.8 \%)$ and $\mathrm{I} 3(\mathrm{II} .6 \%)$ records, respectively.

Table I Subject headings used to index post-graduate I\&KM research

\begin{tabular}{|c|c|c|c|c|c|c|}
\hline \multirow[b]{2}{*}{ No } & \multicolumn{3}{|l|}{ Current and Completed Research database $(\mathrm{N}=210)$} & \multicolumn{3}{|c|}{ Union Catalogue of Theses and Dissertations database $(\mathrm{N}=\mid \mathrm{I} 2)$} \\
\hline & Subject headings & Records & $\%$ & Subject headings & Records & $\%$ \\
\hline I & Information Science & 210 & 100.0 & Knowledge Management & 95 & 84.8 \\
\hline 2 & Information Management & 210 & 100.0 & Organisational Learning & 21 & 18.8 \\
\hline 3 & Business Administration / Business Leadership & 18 & 8.6 & Intellectual Capital & 13 & 11.6 \\
\hline 4 & Business Management & 6 & 2.9 & Strategic Planning & 9 & 8.0 \\
\hline 5 & Library Science & 5 & 2.4 & Information Resources Management & 9 & 8.0 \\
\hline 6 & Personnel Management and Manpower Planning & 3 & 1.4 & Knowledge Management - South Africa & 9 & 8.0 \\
\hline 7 & Management and Information Systems & 3 & 1.4 & Information Technology & 7 & 6.3 \\
\hline 8 & Information Technology & 2 & 1.0 & Organisational Effectiveness & 7 & 6.3 \\
\hline 9 & Public Administration & 2 & 1.0 & Tacit Knowledge & 5 & 4.5 \\
\hline 10 & Personnel Management and Manpower Planning & 2 & 1.0 & Organisational Change & 5 & 4.5 \\
\hline II & Business Management and Policy & 2 & 1.0 & Management Information Systems & 4 & 3.6 \\
\hline 12 & Readership & 2 & 1.0 & Communication In Organizations & 4 & 3.6 \\
\hline 13 & University Libraries & 2 & 1.0 & Project Management & 4 & 3.6 \\
\hline 14 & Training and Education & 2 & 1.0 & Business Planning & 3 & 2.7 \\
\hline 15 & Education & 2 & 1.0 & Competition & 3 & 2.7 \\
\hline 16 & Marketing Management & I & 0.5 & Communities Of Practice & 3 & 2.7 \\
\hline 17 & University Libraries & I & 0.5 & Customer Relations - Management & 3 & 2.7 \\
\hline 18 & Information Economy & I & 0.5 & Industrial Management & 3 & 2.7 \\
\hline 19 & Administration and Management (at Tertiary Level) & I & 0.5 & Expert Systems (Computer Science) & 3 & 2.7 \\
\hline 20 & Engineering Management & I & 0.5 & Customer Services & 3 & 2.7 \\
\hline 21 & Information Analysis and Storage & I & 0.5 & Knowledge Acquisition (Expert Systems) & 3 & 2.7 \\
\hline \multirow[t]{2}{*}{22} & Management and Information Systems & 1 & 0.5 & Information Technology - Management & 3 & 2.7 \\
\hline & & & & Knowledge Representation (Information & & \\
\hline \multirow[t]{2}{*}{23} & Central Government Sector & 1 & 0.5 & Theory) & 3 & 2.7 \\
\hline & Didactics (General) (from Primary To Secondary & & & & & \\
\hline 24 & Level) & 1 & 0.5 & Operations Research & 2 & 1.8 \\
\hline 25 & Computer Science & I & 0.5 & Rule-Based Programming & 2 & 1.8 \\
\hline
\end{tabular}

The outstanding subject headings in I\&KM literature were Information Management, Knowledge Management, Organisational Learning, Intellectual Capital and Business Administration. It is worth noting however that Information Management and Knowledge Management were used to extract records from C\&CR and UCTD, respectively, and as a result the two concepts were expected to yield more records than any other subject heading.

It was also observed that the average number of subject headings used to index I\&KM research projects in UCTD was 1.96 subject headings per record while the 210 records covered in C\&CR contained an average of 0.12 words per record. It follows therefore that more indexing terms were allocated to a given single record in UCTD than C\&CR. If one was to develop a list of terms that can best describe the topics of I\&KM research in South Africa, one is likely to obtain satisfactory results from UCTD. A further examination of the subject heading 'Knowledge Management' and its subheadings indicated that there were instances whereby KM was qualified by other descriptors such as South Africa, which yielded a total of nine documents. Other qualifiers (ie sub-headings) included South Africa - Stellenbosch; South Africa - 
Free State; South Africa - Case studies; Research; Education - Methodology; Economic aspects; Data processing; Case studies; Africa, Southern; and Africa.

Table 2 Most commonly used title words to describe post-graduate I\&KM research in South Africa

\begin{tabular}{|c|c|c|c|c|c|c|c|c|}
\hline \multirow[b]{2}{*}{ No. } & \multicolumn{4}{|c|}{$\operatorname{UCTD}(\mathrm{N}=|| 2)$} & \multicolumn{4}{|c|}{$C \& C R(N=210)$} \\
\hline & Rank & Title words & Records & $\%$ & Rank & Title words & Records & $\%$ \\
\hline$I$ & 1 & Knowledge & 72 & 64.3 & $I$ & Management & 94 & 44.8 \\
\hline 2 & 2 & Management & 64 & 57.1 & 2 & Information & 93 & 44.3 \\
\hline 3 & 3 & Information & 20 & 17.9 & 3 & Knowledge & 77 & 36.7 \\
\hline 4 & 4 & Learning & 12 & 10.7 & 4 & South & 32 & 15.2 \\
\hline 5 & 4 & Study & 12 & 10.7 & 5 & Africa & 26 & 12.4 \\
\hline 6 & 6 & Model & 11 & 9.8 & 6 & Study & 21 & 10.0 \\
\hline 7 & 7 & South & 10 & 8.9 & 7 & Model & 20 & 9.5 \\
\hline 8 & 8 & Business & 8 & 7.1 & 8 & Security & 17 & 8.1 \\
\hline 9 & 8 & Development & 8 & 7.1 & 9 & Case & 14 & 6.7 \\
\hline 10 & 8 & Implementation & 8 & 7.1 & 10 & Framework & 13 & 6.2 \\
\hline II & 8 & Organisation & 8 & 7.1 & 10 & Practice & 13 & 6.2 \\
\hline 12 & 8 & Strategy & 8 & 7.1 & 10 & Services & 13 & 6.2 \\
\hline 13 & 8 & Technology & 8 & 7.1 & 13 & African & 12 & 5.7 \\
\hline 14 & 14 & Africa & 7 & 6.3 & 13 & Environment & 12 & 5.7 \\
\hline 15 & 14 & Competitive & 7 & 6.3 & 13 & Learning & 12 & 5.7 \\
\hline 16 & 14 & Framework & 7 & 6.3 & 16 & System & 11 & 5.2 \\
\hline 17 & 14 & Intellectual & 7 & 6.3 & 17 & Technology & 10 & 4.8 \\
\hline 18 & 14 & Organisations & 7 & 6.3 & 18 & Competitive & 9 & 4.3 \\
\hline 19 & 14 & Practice & 7 & 6.3 & 18 & Development & 9 & 4.3 \\
\hline 20 & 14 & Tool & 7 & 6.3 & 18 & Strategy & 9 & 4.3 \\
\hline
\end{tabular}

Another way of examining the topics of research in any field or discipline is by identifying the common title words, since titles are important components of any scientific article, as they form part of the access points in search and retrieval systems (Yitzhaki 200I: 759). In many cases title words are used to provide indexing and subject terms, especially in automatic indexing. Table 2 provides the most frequently used title words to describe I\&KM research in South Africa as reflected in UCTD and C\&CR databases, respectively.

Topping the list in UCTD is "knowledge" which appeared in a total of $72(64.3 \%)$ titles followed by "management" (64 or $57.1 \%)$ while "information" came a distant third with 20 (I7.9\%). Other words that appeared in I\&KM titles in UCTD were: "learning" (12 or 10.7\%) and "study" (12 or 10.7\%). In the C\&CR database, the most frequent title words were "management" (94 or 44.8\%), "information" (93 or 44.3\%), "knowledge" (77 or 36.7\%), "South" (32 or I5.2\%, and "Africa" (26 or 12.4\%). Apart from the word "development" which did not appear in titles extracted from the UCTD database, all the words in Table 2 were common in both databases, implying some similarities of coverage between the two databases, as well as between "information management" (a term used to index I\&KM records in C\&CR) and "knowledge management" (a term used to index I\&KM records in UCTD).

There were 442 and 749 title words used to discuss I\&KM in UCTD and C\&CR databases, respectively. Out of these, 294 title words were common in UCTD and C\&CR titles, thereby creating a coverage overlap of 0.33 which falls way below the absolute figure of I that normally reflects a perfect relationship. The strength of association between UCTD's and C\&CR's coverage of title words, calculated using Krsul's mathematical formula was 0.26 , which similarly indicates that the relationship between title words as covered in UCTD and C\&CR was weak, thereby implying little similarity.

Figure 2 provides a Freeman-Granovetter Group analysis of the top most common title words. A Freeman-Granovetter grouping technique of network analysis produced I674 absent ties, II strong ties and 8326 weak ties out of the top I42 most frequent title words. According to Hanneman and Riddle (2005), a value of two indicates a strong tie while a one reflects weak ties, and absent ties (ie groups of terms that did not have links with each other) record a value of zero (see examples in Fig 2). Fig 2 lays an emphasis on the words that recorded strong ties. The groups that recorded strong ties, located at the top of Fig 2, are "knowledge" and "management", "South" and "Africa", "study" and "case", "competitive" and "advantage", "intellectual" and "capital", "reference" and "specific", "medium" and "micro", "organisational" and "behaviour", "base" and "expert", "data" and "secure", and "formulation" and "policy". These pairs of words may also 
provide the topics (and the scope - ie geographical and methodological) of I\&KM research by M\&D students in South Africa, namely knowledge management, intellectual capital, organisational behaviour, competitive advantage, South Africa (geographical scope) and case study (ie research method commonly used by post-graduate students in South Africa).

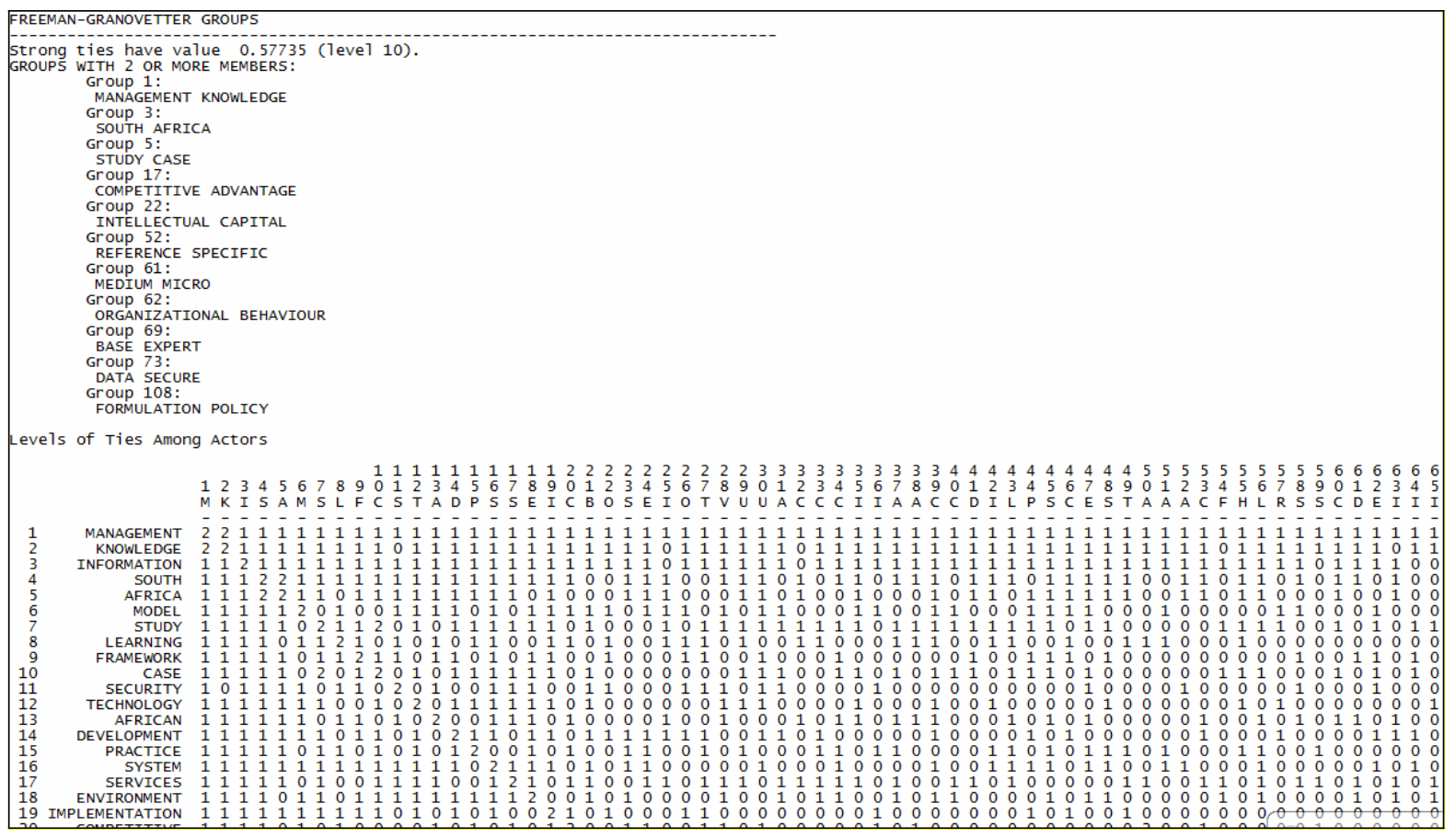

Figure 2 Freeman-Granovetter groups of the top 142 most common I\&KM title words

Figure 2 provides a Freeman-Granovetter Group analysis of the top most common title words. A Freeman-Granovetter grouping technique of network analysis produced I674 absent ties, II strong ties and 8326 weak ties out of the top I42 most frequent title words. According to Hanneman and Riddle (2005), a value of two indicates a strong tie while a one reflects weak ties, and absent ties (ie groups of terms that did not have links with each other) record a value of zero (see examples in Fig 2). Fig 2 lays an emphasis on the words that recorded strong ties. The groups that recorded strong ties, located at the top of Fig 2, are "knowledge" and "management", "South" and "Africa", "study" and "case", "competitive" and "advantage", "intellectual" and "capital", "reference" and "specific", "medium" and "micro", "organisational" and "behaviour", "base" and "expert", "data" and "secure", and "formulation" and "policy". These pairs of words may also provide the topics (and the scope - ie geographical and methodological) of I\&KM research by M\&D students in South Africa, namely knowledge management, intellectual capital, organisational behaviour, competitive advantage, South Africa (geographical scope) and case study (ie research method commonly used by post-graduate students in South Africa).

\subsection{Study leaders behind post-graduate I\&KM research in South Africa}

The frequency counts in the analysis of the output of study leaders was computed using a complete count approach wherein every author was fully counted "whenever he/she appears, whether or not there is multiple authorship" (Diodato 1994: 48).

There was a total sum of 93 senior researchers who had supervised at least one Masters and/or Doctoral projects on I\&KM in South Africa. Table 3, which provides the names of study leaders who have supervised at least three M\&D studies each, shows that the highest frequency count was recorded by Van Der Walt MS who had supervised a total of 23 (11.5\%) post-graduate researches in I\&KM, followed by Du Toit ASA ( 20 or $10.0 \% \%$ ) and Snyman MMM (10 or $5.0 \%)$. Others who supervised I\&KM M\&D studies include, in the descending order: Botha DF (8 or 4.0\%), Van Brakel PA (6 or $3.0 \%$ ), Fouche B (5 or 2.5\%), Ngulube (5 or $2.5 \%)$, Britz JJ (4 or $2.0 \%)$ ), Pottas D (4 or $2.0 \%$ ), Rensleigh CW (4 or 2.0\%). A total of three (I.5\%) studies each were supervised by De Beer CS, Dick AL, Kok JA, Maasdorp CH, Muller HP, Pather M, Underwood PG, and Von Solms R. Those study leaders who had supervised two studies each were: Auret HE, Bothma TJD, Cronje JC, Kaniki AM, Kinghorn J, Minishi-Majanja MK, Smith GJ, Snyman ME, Terblanche F, Theron JC, Van der Walt TB and Wesson JL. The rest of the study leaders contributed only one $(0.5 \%)$ document each. It was interesting 
to note that majority of the study leaders are among South Africa's NRF (National Research Foundation) ${ }^{4}$ rated LIS researchers (see Onyancha \& Ocholla, 2009b). They include Snymann MMM, Van Brakel PA, Ngulube P and Dick AL.

Table 3 Most productive study leaders $(\mathrm{N}=200)$

\begin{tabular}{llll}
\hline No & Study Leader & Number of studies supervised & Percentage \\
\hline 1 & Van der Walt MS & 23 & 11.5 \\
2 & Du Toit ASA & 20 & 10.0 \\
3 & Snyman MMM & 10 & 5.0 \\
4 & Botha DF & 8 & 4.0 \\
5 & Van Brakel PA & 6 & 3.0 \\
6 & Fouche B & 5 & 2.5 \\
7 & Ngulube P & 5 & 2.5 \\
8 & Britz J & 4 & 2.0 \\
9 & Pottas D & 4 & 2.0 \\
10 & Rensleigh CW & 4 & 2.0 \\
11 & De Beer CS & 3 & 1.5 \\
12 & Dick AL & 3 & 1.5 \\
13 & Kok JA & 3 & 1.5 \\
14 & Maasdorp CH & 3 & 1.5 \\
15 & Muller HP & 3 & 1.5 \\
16 & Pather M & 3 & 1.5 \\
17 & Underwood PG & 3 & 1.5 \\
18 & Von Solms R & 3 & 1.5 \\
\hline
\end{tabular}

\subsection{Level and qualification of post-graduate I\&KM research in South Africa}

This section provides information regarding the level of study as well as the qualifications of post-graduate students who were involved in I\&KM research in South Africa, in order to reveal the level at which I\&KM research is commonly conducted as well the most common qualification of post-graduate research in the country. Table 4 indicates that most research was carried out at Masters level, which produced a total $163(77 \%)$ records while the Doctoral research output totalled 48 , accounting for $23 \%$ of total 210 . A similar observation was made by Onyancha (2006) who cited that "[the] majority of studies were conducted at Masters Level of education while there was a favorable representation from the Doctorate candidates" in HIV/AIDS research in South Africa.

In terms of qualification, most research was conducted in the attainment of a Master of Philosophy degree which yielded 34 (16.2\%) records. Masters of Arts in Information Science came second with 23 (11.0\%) followed by general Masters of Arts (2I or 10.0\%), Masters of Technology (19 or $9.0 \%$ ), and general Doctor of Philosophy (I5 or $7.1 \%)$. It was observed that some of the qualifications were actually the same although they were expressed differently. For example, a PhD and a DPhil both refer to a qualification as a Doctor of Philosophy. The qualifications also indicated the disciplines or fields in which I\&KM research is conducted in South Africa. They include Information Science (eg MA in Information Science and DLitt et Phil in Information Science), Technology (MTech, DTech, and DTech: Informatics), Information Systems (eg MIS), Business Information Systems (eg MBIS), Commerce (eg MCom and DCom), Information and Knowledge Management (eg MPhil in Information and Knowledge Management, MA in Information and Knowledge Management and DLitt et Phil in Information and Knowledge Management), Business Administration (eg Masters in Business Administration), Communication Science (eg Masters in Communication), Management (eg Masters in Management), Informatics (eg DTech: Informatics), Media Studies (eg MA in Media Studies), Education (eg MED), Engineering (eg MEng), Decision Making (eg MPhil in Decision Making, Knowledge Dynamics and Values), Information Management (eg MPhil in Information Management), and Computer Science (eg PhD in Computer Science). This pattern is in tandem with the multi-disciplinarity of information and knowledge management, a situation that confirms the observations of several authors (see Jacobs, 2004; Gu, 2004; and Onyancha \& Ocholla, 2006) who opine that scholars from various fields and/or disciplines have of late developed an intense interest in KM.

4. The National Research Foundation of South Africa has a system of rating researchers for purposes of funding. There are six categories of NRF rated researchers, namely leading international researcher; internationally acclaimed researcher; established researcher; NRF President's awardee; promising young researcher; and late entrant into research. For more information about the rating of NRF researchers, see http://evaluation.nrf.ac.zal 
Table 4 Level and qualification of post-graduate I\&KM research in South Africa

\begin{tabular}{|c|c|c|c|}
\hline No. & Qualification & Records & Percentage \\
\hline I & MPhil & 34 & 16.2 \\
\hline 2 & MA (Information Science) & 23 & 11.0 \\
\hline 3 & MA & 21 & 10.0 \\
\hline 4 & MTech & 19 & 9.0 \\
\hline 5 & $\mathrm{PhD}$ & 15 & 7.1 \\
\hline 6 & MIS & 15 & 7.1 \\
\hline 7 & DLitt et Phil & 10 & 4.8 \\
\hline 8 & DPhil & 9 & 4.3 \\
\hline 9 & MBIS & 9 & 4.3 \\
\hline 10 & DTech & 8 & 3.8 \\
\hline II & MCom & 8 & 3.8 \\
\hline 12 & MPhil (Information and Knowledge Management) & 7 & 3.3 \\
\hline 13 & MSc & 5 & 2.4 \\
\hline 14 & MBA & 4 & 1.9 \\
\hline 15 & MBibl & 4 & 1.9 \\
\hline 16 & MA (Information and Knowledge Management) & 2 & 1.0 \\
\hline 17 & $M M(P \& D M)$ & 2 & 1.0 \\
\hline 18 & DCom & 1 & 0.5 \\
\hline 19 & DLitt et Phil (Information and Knowledge Management) & 1 & 0.5 \\
\hline 20 & DLitt et Phil in Information Science & I & 0.5 \\
\hline 21 & DTech: Informatics & 1 & 0.5 \\
\hline 22 & MA in Media Studies & 1 & 0.5 \\
\hline 23 & MBibl & 1 & 0.5 \\
\hline 24 & MComm (Business Management) & 1 & 0.5 \\
\hline 25 & MED & 1 & 0.5 \\
\hline 26 & MEng & 1 & 0.5 \\
\hline 27 & MPhil (Decision Making, Knowledge Dynamics and Values) & 1 & 0.5 \\
\hline 28 & MPhil (Information Management) & 1 & 0.5 \\
\hline 29 & MSc (CWRR) & 1 & 0.5 \\
\hline 30 & MSc (Information Systems) & 1 & 0.5 \\
\hline 31 & $\mathrm{PhD}$ (Computer Science) & 1 & 0.5 \\
\hline 32 & $\mathrm{PhD}$ (Management) & I & 0.5 \\
\hline
\end{tabular}

4.5 Institutions behind post-graduate I\&KM research in South Africa

An analysis of the records in terms of the contributing institutions (see Fig 3) indicated that a total of 17 institutions contributed to I\&KM research in South Africa, with the University of Stellenbosch (SU) leading the pack with 47 (22.4\%) records out of the total 210 records extracted from C\&CR, followed by the University of Johannesburg (UJ) (37 or 17.6\%), Nelson Mandela Metropolitan University (NMMU) (36 or 17.1\%), the University of Pretoria (UP) (25 or 1I.9\%), the University of South Africa (UNISA) (23 or II.0\%), and the University of KwaZulu-Natal (UKZN) (II or $5.2 \%)$, just to name the institutions that had contributed over 10 records each. The rest of the institutions contributed less than 10 records each. Perhaps, it is not surprising that $\mathrm{SU}$ and $\mathrm{UJ}$ topped the list of the most productive universities as the two universities' departments of LIS have since changed their curriculum to offer I\&KM - specific programmes/ qualifications. Other universities that contributed a higher number of I\&KM research are those offering KM programs, although not necessarily through the departments of LIS as some of the universities do not have LIS departments (eg NMMU, Wits and TUT). However, the majority of the most productive universities have departments that offer LIS qualifications (ie UP, UNISA, UKZN, UCT and UWC).

The universities that did not feature in Fig 3 are the University of the Free State (UFS), the University of Limpopo (UL), Durban University of Technology (DUT), Mangosuthu University of Technology (MUT), Vaal University of Technology (VUT), the University of Venda (UNIVEN), and the Walter Sisulu University for Technology and Science (WSU). The majority of these universities (ie 4 out of 7) are universities of science and/or technology, a factor that may 
have influenced their lack of contribution to I\&KM research, which is largely regarded as a humanities and/or social science discipline although the offerings in Table 4 depict otherwise. Despite the fact that UL and DUT offer LIS programs/qualifications, they did not produce any I\&KM research at Masters or Doctoral level.

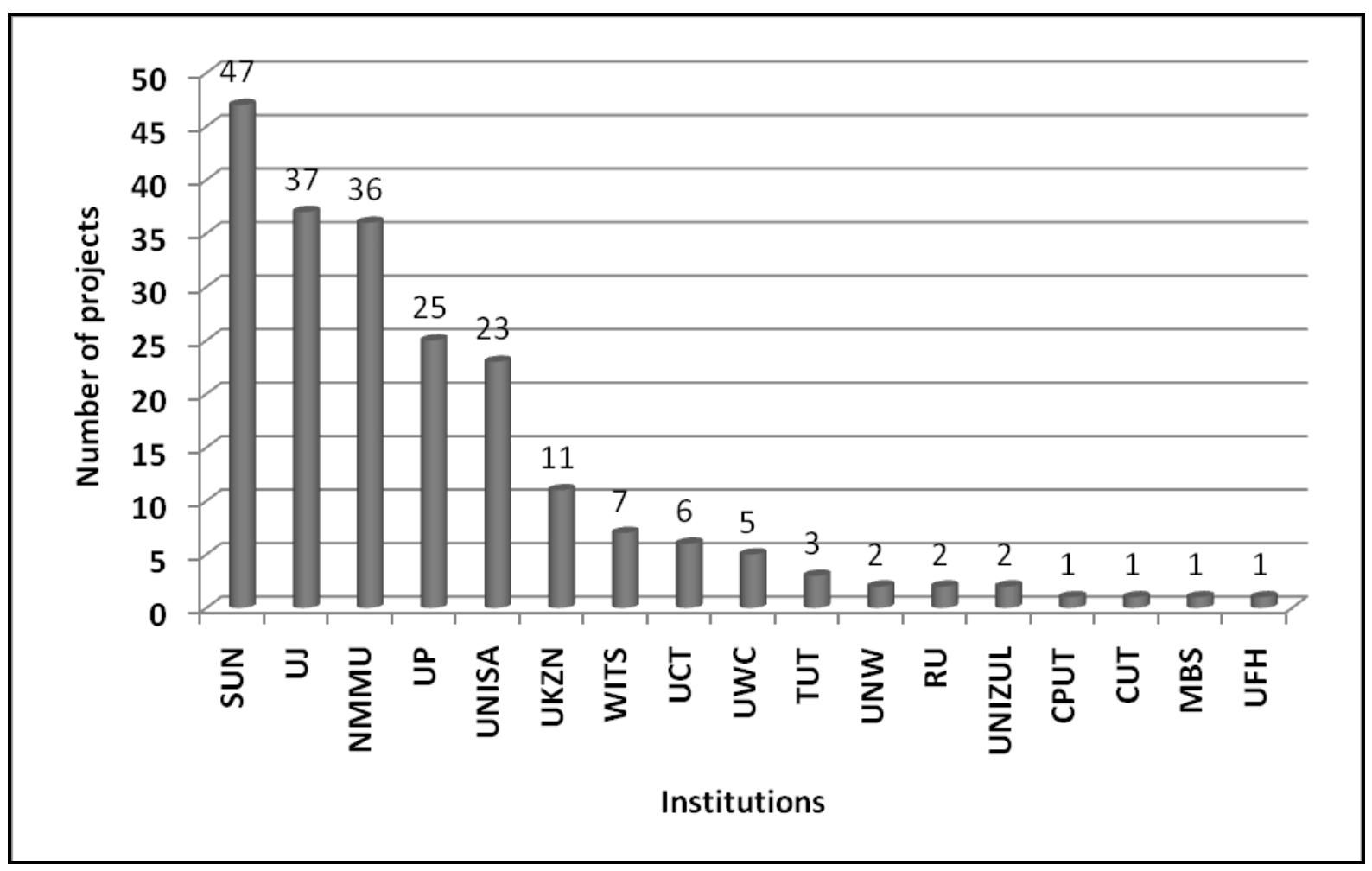

Figure 3 Institutions behind I\&KM post-graduate research in South Africa

\subsection{Trends in post-graduate research in I\&KM in South Africa}

Fig 4 shows trends in post-graduate research in I\&KM in South Africa as indexed in C\&CR and UCTD databases, respectively. The illustration shows that the first I\&KM research was completed in 1995 which recorded one posting and that there was no research completed in the next three years until 1999 in which one M\&D research was completed. Thereafter, there was increased activity in I\&KM research with the year 2000 recording four and five M\&D research projects in C\&CR and UCTD, respectively. The distribution of records in terms of the other years, for C\&CR and UCTD respectively was: 200 I (3, 6), 2002 (I2, 9), 2003 (I4, 9), 2004 (17, I6), 2005 (25, 2I), 2006 (I2, 2I), 2007 (9, I9), 2008 $(14, \mathrm{II})$, and $2009(2, \mathrm{I})$. This pattern reveals that which has already been observed, namely that researchers in South Africa started taking interest in KM in around 1996 (Ondari-Okemwa \& Minishi-Majanja, 2007). It is also evident that the pattern of completion of I\&KM research is typical of research in emerging areas whereby at the beginning, the absolute number of publications is small and the growth rate shows signs of increasing (Crane in Jacobs, 2004). After the initial stage, Crane as cited in Jacobs (2004: $2 \mathrm{II}$ ) opines that there are three additional distinct stages of growth, namely

- the emergence of a period of growth, during which time the absolute number of publications grows exponentially (doubling the number of publications at regular intervals) and the growth rate is constant and large

- a subsequent stage, during which the annual growth of publications returns to being incremental and the growth rate shows signs of decline

- a further stage wherein the growth rate and absolute number of publications decline to zero.

It seems as though I\&KM at post-graduate level in South Africa is following Crane's pattern or stages of growth. Whereas the percentage growth of I\&KM records portray a different picture (in terms of which there is an upwards/downwards pattern of growth), the number of records has continued to increase since the mid-1990s to peak at 25 in 2005 (C\&CR) and 37 in 2007 (UCTD). Thereafter there was a general and continued decline in both cases. Is this the beginning of the end of I\&KM post-graduate research in South Africa? Although this question cannot be conclusively answered, it can be argued that the decline witnessed in 2008 and 2009 can be attributed partly to the indexing time lag that exists between 
the time a record is published and the time it is actually indexed in any given database. As a result, we believe that majority of the 2008 and 2009 I\&KM research projects are yet to be indexed in the two databases. Underscoring the importance of the indexing time lag, Diodato (1994: 157) observes thus:

Indexing time lag is a measure of how quickly an indexing service indexes materials. So, this measure is often an average of the time lags for many articles. Indexing time lag can be used to compare the efficiency of two indexing services or to compare how one indexing service processes articles from various journals.

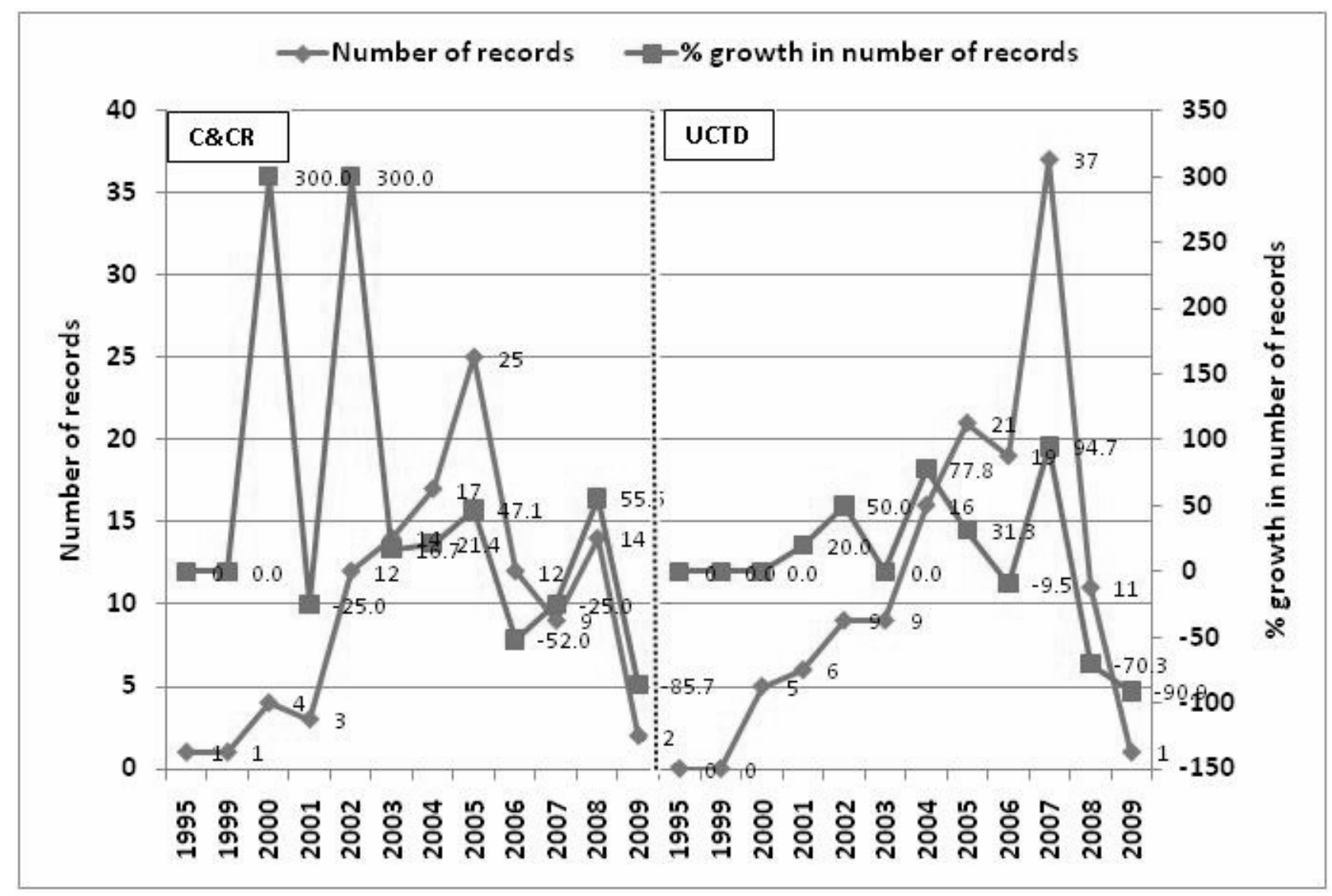

Figure 4 Trend of I\&KM research by post-graduate students in South Africa

It seems as though I\&KM at post-graduate level in South Africa is following Crane's pattern or stages of growth. Whereas the percentage growth of I\&KM records portray a different picture (in terms of which there is an upwards/downwards pattern of growth), the number of records has continued to increase since the mid-1990s to peak at 25 in 2005 (C\&CR) and 37 in 2007 (UCTD). Thereafter there was a general and continued decline in both cases. Is this the beginning of the end of I\&KM post-graduate research in South Africa? Although this question cannot be conclusively answered, it can be argued that the decline witnessed in 2008 and 2009 can be attributed partly to the indexing time lag that exists between the time a record is published and the time it is actually indexed in any given database. As a result, we believe that majority of the 2008 and 2009 I\&KM research projects are yet to be indexed in the two databases. Underscoring the importance of the indexing time lag, Diodato (1994: 157) observes thus:

Indexing time lag is a measure of how quickly an indexing service indexes materials. So, this measure is often an average of the time lags for many articles. Indexing time lag can be used to compare the efficiency of two indexing services or to compare how one indexing service processes articles from various journals.

\section{Conclusions and recommendations}

Although it was not the subject of investigation in the current study, it was observed that the use of information management, on the one hand, and knowledge management, on the other hand, when indexing information and knowledge management literature in the two databases, is quite chaotic. This reflects the global confusion that exists when defining knowledge management. The Association for Library and Information Science Education (ALISE) (2007), in 
its list of categories of LIS research areas, classifies knowledge management under organisation of information and not in the management/administration category. Similarly, C\&CR has allotted class number 658.4 to the majority of KM theses and dissertations. The DDC call number 658.4, as the classification number is commonly known in library practice, is used to classify publications on executive management. Generally, class 658 describes general management resources. The DDC (20I I) outlines the topics covered under class 658 as follows:

- 658.00I Philosophy and theory

- 658.002 Miscellany

- 658.02 Small enterprises

- 658.I Organisation and financial management

- 658.2 Plant management

- 658.3 Personnel management (Human resource management)

- 658.4 Executive management

- 658.5 Management of production

- 658.7 Management of materials

- 658.8 Management of marketing

This aspect requires further research and/or discourse so as to have a proper universal understanding of the scope of KM. Without such a grounded knowledge of KM, it will be very difficult for study leaders to supervise researches conducted in the subject area. Perhaps it would also be beneficial to researchers if a common thesaurus with a standardised and controlled vocabulary could be used to index contents in the SABINET hosted databases for the purposes of uniformity. In that way, a uniform search across a number of databases would yield satisfactory results.

Concerning the post-graduate research output in KM in South Africa, it was noted that there is a remarkable increase as reflected in the number of projects being completed every year. From just four and five completed researches in 2000 , the number has grown to peak at 25 and 37 in 2005 and 2007 in C\&CR and UCTD, respectively. However, a comparative study to investigate the research output of M\&D students across not only the fields of LIS but across disciplines is highly recommended. Such comparison will assist in gauging whether or not the growth of I\&KM research witnessed in the current study can be said to be impressive. In terms of the subjects/topics of research, the study has confirmed various writers' observations that I\&KM is a multidisciplinary field, drawing its researchers from different disciplines. This aspect was also reinforced by the variety of qualifications in which I\&KM research is conducted. This study found that I\&KM research is conducted in pursuit of two qualifications in 31 subject specialisations. The number of disciplines in which I\&KM research is carried out as identified in the analysis of the qualifications was I6 (see Table 4). There were a total of 93 study leaders who had supervised at least one student conducting research in I\&KM in South Africa. We believe that this number of senior researchers is too small given that $\mathrm{KM}$ has continued to attract scholars and students from various sectors of the South African society.

With regard to the most productive institutions, it can be concluded that the previously advantaged universities continue to dominate not only in the national research output but also in I\&KM research. Three distinct clusters emerged in the analysis of the institutions engaged in M\&D research in I\&KM in South Africa. The first cluster of the most productive institutions consisted of three universities, namely the University of Stellenbosch, the University of Johannesburg and Nelson Mandela Metropolitan University. The second cluster comprised the University of Pretoria, the University of South Africa and the University of KwaZulu-Natal. The final cluster consisted of a total of I I institutions that are least active in M\&D research in I\&KM in the country. These are the University of the Witwatersrand, the University of Cape Town, the University of the Western Cape, Tshwane University of Technology, the North-West University, Rhodes University, the University of Zululand, the Cape Peninsula University of Technology, the Central University of Technology, Milpark Business School, and the University of Forth Hare. Of particular concern but not investigated in this study is the nature of Masters dissertations (i.e. limited scope or full dissertation) produced by the students. A qualitative survey of the issue will provide underlying factors that resulted in the patterns witnessed in the analysis of institutional and individual study leaders' productivity.

Finally, post-graduate I\&KM research is largely conducted at Masters level as opposed to doctoral level. This is in line with international trends where student enrolment is higher at Masters level than doctoral level, particularly in situations where academic departments or schools and, by extension institutions, offer the two programmes. The opposite would be expected if the same departments and institutions offered $\mathrm{PhD}$ programmes only.

SA Jnl Libs \& Info Sci 20II, 77(2) 


\section{Acknowledgements}

A version of this paper was delivered at the $10^{\text {th }}$ Annual Information and Knowledge Management Conference, University of Johannesburg, South Africa, 22-23 June 20II. The support offered towards refining the article by reviewers is highly appreciated.

\section{References}

ALISE (Association for Library and Information Science Education). 2007. LIS research areas classification scheme. [Online]. http://www.alise.org/mc/page.do?sitePageld=55727. (Accessed I7 May 20I I).

Byrnes, G. 2010 . From the Pro Vice Chancellor (Postgraduate). Higher Degrees Newsletter. [Online]. http://www.waikato.ac.nz/ sasd/postgraduate/newsletter/sept2010.html. (Accessed 29 March 20I I).

Coulter, N., Monarch, I and Konda, S. 1998. Software engineering as seen through its research literature: a study in co-word analysis. Journal of the American Society for Information Science, 49(I 3): I 206-I 223.

Dewey Decimal Classification (DDC). 201 I. General management. [Online]. http://dewey.info/class/658/about.en. (Accessed 29 March 20II).

Diodato, V. 1994. Dictionary of Bibliometrics. New York: Haworth.

Gu, Y. 2004. Global knowledge management research: a bibliometric analysis. Scientometrics, 6I (2): I 7 I- 190.

Hanneman, R and Riddle, M. 2005. Introduction to social network methods: (free introductory textbook on social network analysis. [Online]. http://faculty.ucr.edu/ hanneman/. (Accessed 4 May 20I I).

Jacobs, D. 2004. Growth and development in knowledge management research: a bibliometric study. In: Kaniki, A \& Bothma, T.J.D. (eds). Proceedings of the $3^{\text {rd }}$ biennial DISSAnet Conference. Pretoria: Infuse, pp. 2I I-220.

Krsul, I. 2002. Co-word analysis tool. [Online]. http://www.acis.ufl.edu/ ivan/coword/algorithmdescription.pdf. (Accessed 3 December 2003).

Ocholla, D.N. \& Bothma, T. 2007. Library and information education and training in South Africa. In: T. Bothma, P. Underwood and P. Ngulube (eds). Libraries for the future: progress and development of South African libraries. Pretoria: Library and Information Association of South Africa (LIASA), pp I49-168.

Ondari-Okemwa, E and Minishi-Majanja, M.K. 2007. Knowledge management education in the departments of library/ information science in South Africa. South African Journal of Libraries and Information Science, 73(2): I36-I46.

Onyancha, O.B. 2006. Empowering the South African community in the AIDS war: an informetric-case study of HIV/AIDS research projects, with special reference to masters and doctoral dissertations and theses. South African Journal of Libraries and Information Science, 7I(2): 56-7I.

Onyancha, O.B. and Ocholla, D.N. 2006. Trends and patterns of 'Knowledge Management' research in South Africa: an informetric analysis of tacit and explicit knowledge management: A paper presented at the SCECSAL conference, Dar es Salaam, Tanzania, July 2006. In: XVII Standing Conference of Eastern, Central \& Southern Africa Library \& Information Associations (SCECSAL XVII). Dar es Salaam: The Library and Information Association of Tanzania, pp. 338-36I.

Onyancha, O.B. and Ocholla, D.N. 2007. Country-wise collaborations in HIV/AIDS research in Kenya and South Africa, 19802005. Libri, 57(4): 239-254.

Onyancha, O.B. and Jacobs, D. 2009. Capacitating national research: a review of South African natural sciences research projects, theses and dissertations, 1986-2006. South African Journal of Libraries and Information Science, 75(2): II 7 - I 30.

Onyancha, O.B. and Ocholla, D.N. 2009a. Conceptualizing 'knowledge management' in the context of library and information science using the core/periphery model. South African Journal of Information Management, I I (4): I-I 5.

Onyancha, O.B. and Ocholla, D.N. 2009b. Assessing researchers' performance in developing countries: is Google Scholar an alternative? Mousaion, 27(I): 43-64.

Raju, J. 2004. First level library and/or information science qualifications at South African universities and technikons: a comparative study of curricula. South African Journal of Libraries and Information Science, 70(I): 9-19.

Raju, J. 2005. First level library and/or information science education and training at South African universities and technikons: developments in specialization. South African Journal of Libraries and Information Science, 7I (2): I64-I 74.

University of Johannesburg. Department of Information and Knowledge Management. 2010. About us. [Online]. http:// www.uj.ac.za/EN/Faculties/management/departments/infoman/about/Pages/default.aspx. (Accessed 4 April 20I0).

University of Stellenbosch. Centre for Knowledge Dynamics and Decision Making. 2009. Welcome. [Online]. http:// www.informatics.sun.ac.za/index.php?page=home. (Accessed 4 April 2010).

Yitzhaki, M. 200I. Relation of title length of journal article to length of article. In: M. Davis and C.S. Wilson (eds). Proceedings of the 8th International Conference on Scientometrics and Informetrics. Sydney: ISSI, 2, pp. 759-769. 